\title{
A UBERIZAÇÃO DAS RELAÇÕES TRABALHISTAS: O SIMULACRO DO EMPREENDEDORISMO INDIVIDUAL DIANTE DE UM VÍNCULO DE TRABALHO
}

\section{THE UBERIZATION OF LABOR RELATIONS: THE SIMULACRUM OF INDIVIDUAL ENTREPRENEURSHIP IN THE FACE OF A JOB BOND}

\author{
Maria Teodora Rocha Maia do Amaral
}

RESUMO: O novo paradigma tecnológico instituído por empresas como a Uber e o Ifood revolucionou o modo de consumo da sociedade e instituiu novas relações jurídicas. Para essas empresas, não há vínculo laboral entre os seus motoristas/entregadores, o que desobriga a garantia dos direitos trabalhistas presentes no ordenamento jurídico doméstico. Nos tribunais e cortes superiores, no entanto, não há consenso acerca do tipo de vínculo existente. A partir desse cenário jurídico, o objetivo geral do trabalho é analisar a redefinição das relações laborais a partir da situação dos motoristas/entregadores de aplicativos. A investigação se baseou na jurisprudência doméstica e na literatura que discute o objeto a partir das revoluções tecnológicas. Concluiu-se que essa situação jurídica que gera uma zona de incerteza e ambiguidade precariza as condições de trabalho desses empregados e relativiza direitos garantidos perante a ordem constitucional.

Palavras-chave: Direito do Trabalho, Uberização, Direito Constitucional, Revoluções Tecnológicas.

\begin{abstract}
The new technological paradigm instituted by companies like Uber and Ifood revolutionized society's consumption mode and instituted new legal relationships. For these companies, there is no employment relationship between their drivers/deliverers, which releases the guarantee of labor rights present in the domestic legal system. In the courts and higher courts, however, there is no consensus on the type of bond that exists. Based on this legal scenario, the general objective of the work is to analyze the redefinition of labor relations based on the situation of application drivers/deliverers. The investigation was based on domestic jurisprudence and literature that discusses the object from the technological revolutions. It was concluded that this legal situation, which generates an area of uncertainty and ambiguity, precarious the working conditions of these employees and puts the guaranteed rights into perspective in the constitutional order.
\end{abstract}

Key-words: Labor Law, Uberization, Constitutional Law, Technological Revolutions.

\section{INTRODUÇÃO}

A luta secular das entidades sindicais e das organizações de trabalhadores buscou estabelecer 
condições mínimas de trabalho e resultou em uma ampla proteção constitucional e infraconstitucional para a classe. Dentre os diversos fundamentos presentes na Constituição Federal de 1988 que guiaram a estruturação do próprio Estado Democrático brasileiro, destaca-se a dignidade humana e os valores sociais do trabalho. $\mathrm{O}$ que também reflete o patamar jurídico atribuído à proteção da classe trabalhadora é a existência de diversas outras disposições no direito doméstico, sendo possível encontrar um amplo rol de garantias nos direitos fundamentais, nos direitos sociais e na legislação específica da temática. No entanto, as condições laborais foram transformadas em decorrência das revoluções tecnológicas do século XXI que trouxeram mudanças estruturais na sociedade, na economia, nas relações interpessoais, no mundo jurídico e na própria dinâmica social.

O avanço econômico mostrou-se indissociável da inovação tecnológica. Isso gerou um crescimento exponencial na utilização da tecnologia tanto no cotidiano das pessoas, como nos setores de mercado e de consumo. Um dos efeitos inevitáveis dessa conjuntura foi a ascensão de um novo contexto histórico marcado, sobretudo, pela virtualização das relações sociais (incluindo as laborais) e pela instrumentalização da tecnologia para atender às demandas mais cotidianas da vida, como a necessidade de recorrer a um transporte urbano. As leis trabalhistas, criadas em uma sociedade industrializada e sob uma ótica fordista, enfrentam conflitos ao serem (ou tentarem) aplicadas nas novas relações empregatícias que sobrevieram na sociedade da informação, já que, apesar delas coexistirem com as formas tradicionais de trabalho, houve o surgimento de novos tipos de empregadores e de cenários de admissão. Se, antes, uma contratação envolvia entrevistas presenciais e a entrega de um currículo, hoje, é possível fazê-la de maneira totalmente virtual e sem contato humano. Isso evidencia que é inconciliável com a sociedade informacional em vigor aplicar a mesma interpretação dada há décadas sobre o alcance, a potencialidade e os limites das normas trabalhistas.

A empresa Uber destaca-se por, utilizando apenas um aplicativo de celular, ser uma prestadora de serviços eletrônicos na área do transporte privado e a responsável por intitular o fenômeno da "uberização"1. O termo descreve uma relação em que, de acordo com a empresa, há autonomia nas formas de prestação do serviço, flexibilidade do horário, possibilidade de empreender individualmente e ausência de subordinação do motorista. Na prática, os seus motoristas são reconhecidos como "parceiros" e não empregados, o que desobriga a empresa a assegurar uma série de direitos e garantias trabalhistas, como o salário mínimo.

Essa estratégia não é exclusiva da Uber e é utilizada por outra startup, a empresa Ifood. Assim como a Uber, o Ifood utiliza a tecnologia como viabilizadora da sua existência: por meio de um aplicativo que dispõe de vários restaurantes, possibilita a entrega de alimentos utilizando apenas uma solicitação pela internet. Sob o pretexto de ausência de subordinação, os entregadores do aplicativo também não são reconhecidos como empregados, mas como "parceiros" que contribuem para o funcionamento da empresa. Assim, se consubstancia a premissa: se não existe vínculo de trabalho, não incide a legislação trabalhista.

\footnotetext{
${ }^{1}$ Termo utilizado por Gerald F. Davis (2016, p. 502): "More recently we have seen Uberization, which allows on-demand labor to be contracted by the task via online platforms. Uberization threatens to turn jobs into tasks, to the detriment of labor. Every input into the enterprise becomes possible to rent rather than to buy, and employee-free organizations are increasingly feasible. Enterprises increasingly resemble a web page, a set of calls on resources that are assembled on demand to create a coherent performance."
} 
Os diversos embates jurídicos e casos que ganharam notoriedade revelaram, no entanto, que não há um consenso doutrinário em relação à questão. Apesar da posição enfática e reiterada das empresas em negar que se trata de um vínculo trabalhista, a jurisprudência brasileira já se posicionou tanto de maneira convergente, como também divergente em relação à (in)existência do vínculo laboral nessa situação. Essa margem de subjetividade, além de gerar insegurança jurídica e a possível negação da garantia de direitos, dificulta o processo de formação da identidade dessa categoria de trabalhadores que não conseguem definir o que, de fato, são. O que não impediu mesmo no cenário jurídico ambíguo de haver constantes mobilizações, aos quais se intensificaram durante a pandemia da Covid-192.

O objetivo geral do trabalho é analisar a redefinição das relações laborais a partir da situação dos motoristas/entregadores de aplicativos. A pesquisa divide-se em dois momentos: a) primeiro, será analisada a ressignificação das relações trabalhistas decorrentes do avanço tecnológico e como as empresas Uber e Ifood estão inseridas nesse contexto; b) Após essa contextualização, haverá o levantamento da jurisprudência doméstica para entender como os tribunais interpretam a relação jurídica desempenhada pelos aplicativos e seus funcionários. Para concretizar esses objetivos, utilizou-se fontes bibliográficas, jurisprudenciais e documentais. As primeiras foram produções científicas que tratam da temática em comento e, as segundas, decisões do Tribunal Superior do Trabalho (TST), como também das instâncias inferiores. Também foram utilizadas matérias veiculadas em jornais de grande circulação para aferir a repercussão na sociedade civil dessa controvérsia.

Essa nova relação jurídica advinda das Revoluções Tecnológicas, apesar de inédita, assevera o grau do comprometimento do Estado em relação à pauta dos direitos trabalhistas. Mais do que um conflito existente entre a colisão - natural e inevitável - da tecnologia com os padrões empregatícios mantidos há décadas, é também uma mostra de qual é o estágio da proteção (e da capacidade de adaptação) que a ordem legal trabalhista dispõe. A sociedade, incapaz de ser estática, demanda um direito que acompanhe a sua dinamicidade e as suas transformações humanas.

\section{OS APLICATIVOS UBER E IFOOD: A MODIFICAÇÃO DAS RELAÇÕES TRABALHISTAS A PARTIR (E POR MEIO) DATECNOLOGIA}

No dia 01 de julho de 2020, houve a paralisação nacional dos entregadores de aplicativo, conhecida como "Breque dos Apps". O protesto não se originou do pedido de reconhecimento da relação empregatícia e a consequente demanda de direitos como a carteira assinada e o salário mínimo, apesar de ser também uma

\footnotetext{
${ }^{2}$ Em 11 de março de 2020, a Organização Mundial da Saúde (OMS) caracterizou o surto da doença causada pelo novo coronavírus (COVID-19) como uma pandemia. A circunstância pandêmica forçou os Estados a tomarem uma série de medidas excepcionais como a aprovação de legislações temporárias e a adoção de métodos de isolamento/distanciamento social. Os impactos causados pela abrupta mudança estrutural da sociedade atingiram de maneira geral a coletividade, o que repercutiu, inevitavelmente, na economia. Um dos resultados no setor econômico, que será analisado em momento oportuno, foi atestar as vulnerabilidades que os entregadores e motoristas de aplicativo estavam submetidos (apesar de preexistentes à pandemia, essas vulnerabilidades foram catalisadas sob a sua vigência).
} 
pauta incluída pelo movimento (FOLHA DE SÃO PAULO, 2020a). Porém, as demandas consensualmente pleiteadas apontam para a degradação das condições do serviço prestado sob diversas perspectivas. De acordo com a Folha de São Paulo (2020b), os entregadores desempenham longas jornadas (chegando até a $12 \mathrm{~h}$ diárias) e com a taxa de entrega cada vez menor, o que demandou a reivindicação do aumento do valor por quilômetro rodado, do pagamento mínimo e do fim dos bloqueios injustificados no aplicativo. Essa situação foi agravada pela pandemia da COVID-19, já que as medidas de isolamento social limitaram a circulação das pessoas e aumentaram consideravelmente a demanda pelo serviço desses entregadores.

A pandemia da COVID-19 impactou os entregadores e motoristas de aplicativo de maneiras diferentes, mas igualmente danosas. O Estado brasileiro possui altos índices de desigualdade econômica aos quais, somados à crise humanitária derivada do estado pandêmico, acarretam o aumento nas taxas de desemprego, a intensificação da exclusão social, o acentuamento das disparidades econômicas e a precarização das relações de trabalho (MORAIS; AMARAL; REIS, 2020). O isolamento social, necessário como medida de contenção do avanço da pandemia, beneficiou o aplicativo Ifood por ter aumentado consideravelmente a sua demanda por entregas. Ao mesmo tempo, ocasionou o aumento no número de cadastros de entregadores $^{3}$ e a consequente desvalorização da taxa recebida pelas entregas ${ }^{4}$. Por outro lado, a impossibilidade da circulação de pessoas pelas cidades, a adoção do home-office e a quarentena realizada nas residências diminuíram consideravelmente o número de solicitações de viagens o que deixou os motoristas de aplicativos de transporte urbano expostos à ausência de remuneração.

Contudo, essa precarização das condições de trabalho, apesar de ter sido potencializada pela pandemia, é anterior ao estado pandêmico e já gerou uma série de mobilizações de motoristas do aplicativo Uber. Uma greve mundial dos motoristas da referida empresa ocorreu no dia 10 de maio de 2019. Enquanto a Uber conseguiu aumentar exponencialmente o seu valor de mercado, os motoristas não recebem aumento na remuneração há anos e estão tendo dificuldade em manter as viagens e conseguir cobrir os gastos advindos das manutenções dos carros e do valor do combustível (UNIVERSO ONLINE, 2019). Esse protesto pleiteava o estabelecimento de uma tarifa básica cobrada ao passageiro, o aumento no valor por quilômetro rodado e condições mais seguras de exercício da profissão. Esse cenário representa uma das facetas da dinâmica mercadológica capitalista: ela permite o crescimento da economia empresarial mesmo enquanto os funcionários da empresa estão submetidos a condições degradantes e precárias de serviço.

\footnotetext{
${ }^{3 /}$ No iFood, a fila de espera de entregadores registrou seu pico nos últimos 60 dias. De março a junho deste ano, a plataforma recebeu 480 mil novos cadastros e não deu conta de absorver todo mundo. O número é mais de três vezes a quantidade de entregadores que estavam habilitados em fevereiro (131 mil), antes da pandemia. Em março, os entregadores passaram a 170 mil.” (REVISTA PEQUENAS EMPRESAS E GRANDES NEGÓCIOS, 2020).

4 "Abílio afirmou que, apesar de lucrarem mais, as empresas não têm responsabilidade em relação aos motofretistas e que o ideal é que elas oferecessem um programa de bonificações para incrementar a renda dos trabalhadores. Segundo a pesquisa apontou, $89,7 \%$ deles tiveram uma redução salarial durante a pandemia ou ganham o mesmo que antes. Apenas $10,3 \%$ relataram um aumento." (BBC, 2020).
} 
A tecnologia utilizada por essas empresas está enquadrada no conceito de inovação disruptiva ${ }^{5}$. A Uber é uma empresa que representa, de maneira exemplar, as possibilidades geradas pela tecnologia e é assim que os seus fundadores a descrevem: uma empresa de tecnologia, e não de transportes (UBER, 2019). Por um aplicativo de celular, o tráfego de várias cidades e países foi revolucionado. Kramer (2017) lista uma série de requisitos para ser um motorista parceiro da Uber: é preciso que o interessado seja motorista profissional, com uma carteira de habilitação que permita o exercício de atividade remunerada (EAR) e que também apresente certidões negativas de antecedentes criminais. Ainda segundo a autora, após a realização do cadastro e a aprovação pela empresa, o motorista já começa a atender os usuários que solicitarem uma viagem através do aplicativo.

Após estarem aptos e serem motoristas parceiros do aplicativo, o principal trunfo alegado pela empresa é a possibilidade de ter um horário flexível, pois não existe tempo mínimo para utilização do aplicativo. Nos Termos de Uso ${ }^{6}$ que regem o acesso e a utilização da plataforma, é destacado que a empresa não é fornecedora de bens, não realiza a prestação de serviços de transporte ou de logística, nem, tampouco, atua como transportadora. De acordo com a empresa, todos esses serviços são prestados por "parceiros" independentes que estão empreendendo individualmente e que, portanto, não são empregados e não representam a Uber.

A campanha de marketing amplamente divulgada no site institucional ${ }^{7}$ reforça o empreendedorismo individual da relação e utiliza frases como "seja dono do seu próprio destino", "ganhe dinheiro no seu tempo", "lucre mais no dia a dia" e "ganhe dinheiro na primeira viagem". Tudo isso endossa a ideia sustentada de que não existe vínculo trabalhista entre ela e o motorista, servindo apenas como uma plataforma tecnológica que possibilita o contato dele com o cliente que o serviço será prestado. A única perspectiva na qual "seja dono do seu próprio destino" é cabível ao analisar a situação dos motoristas do aplicativo é quando se leva em conta que não há nenhum tipo de auxílio financeiro em relação à aquisição ou à manutenção (incluindo os valores destinados a colocar combustível) do veículo que será utilizado nas viagens. O motorista assume (sem a possibilidade de negociação) todos os encargos (inclusive jurídicos ${ }^{8}$ ) provenientes da função, apesar de desempenhar o trabalho que viabiliza a subsistência da plataforma. A plataforma digital possibilita a

\footnotetext{
${ }^{5}$ Termo utilizado a primeira vez pelo professor Harvard Clayton M. Christensen. Em sua teoria, a inovação disruptiva, descreve um processo pelo qual um produto ou serviço se enraíza inicialmente em um eixo inferior de um mercado e, em seguida, move-se implacavelmente substituindo os concorrentes estabelecidos (CHRISTENSEN, 2020). O conceito não significa que a inovação tecnológica irá, necessariamente, trazer algo revolucionário, mas que isso chegará a uma maior quantidade de pessoas.

${ }^{6}$ Cujo endereço está registrado no seguinte link: https://www.uber.com/legal/pt-br/document/?name=general-terms-ofuse \&country=brazil\&lang=pt-br

${ }^{7}$ É possível acessá-lo em: https://www.uber.com/br/pt-br/drive/how-it-works/.

${ }^{8}$ Ao se cadastrar no aplicativo é obrigatório aceitar, sem possibilidade de negociação, a seguinte limitação de responsabilidade presente nos Termos de Uso: “A uber não será responsável por danos indiretos, incidentais, especiais, punitivos ou emergentes, inclusive lucros cessantes, perda de dados, danos morais ou patrimoniais relacionados, associados ou decorrentes de qualquer uso dos serviços ainda que a uber tenha sido alertada para a possibilidade desses danos. [...] A uber não será responsável por atrasos ou falhas decorrentes de causas fora do controle razoável da uber e, tampouco, pela qualidade e integridade dos bens disponibilizados por parceiros independentes. você reconhece que parceiros independentes que prestarem serviços de transporte solicitados por meio de algumas marcas poderão oferecer serviços de transporte do tipo "divisão de viagem" (ridesharing) ou ponto a ponto (peerto-peer)."
} 
mediação entre o consumidor e a empresa e faz com que a maior parte do lucro seja destinada a Uber, mesmo difundindo a ideia de que os motoristas são empresários individuais. Os verdadeiros responsáveis pelo funcionamento do aplicativo são os motoristas que, com sua força de trabalho, realizam a função ao qual ele se propõe.

$\mathrm{O}$ art. $3^{\circ}$ da Consolidação das Leis de Trabalho (CLT), determina como empregado toda pessoa física que prestar serviços de natureza não eventual, com subordinação e sob onerosidade. Para configurar uma relação laboral, é necessário exercer a atividade de maneira pessoal, já que o empregado atua pessoalmente. A habitualidade indica que a prestação dessa tarefa não pode ser eventual, mas certa, clara e corriqueira. Além disso, a subordinação representa a hipossuficiência do empregado, que é inferior (hierarquicamente) em relação ao seu empregador. Por fim, para haver o vínculo laboral, é necessário existir onerosidade, que é representada pelo pagamento entregue em decorrência da realização da atividade.

Segundo Kramer (2017), há uma série de fatos envolvendo a relação da Uber com o motorista que fazem com que o vínculo empregatício esteja configurado. Entre eles: o fato da Uber entrevistar e recrutar motoristas (i); a exigência de que motoristas aceitem viagens e/ou não cancelem, gerando a desconexão dos que violarem a determinação (ii); o poder que Uber se reserva em alterar unilateralmente os termos contratuais em relação aos motoristas (iii); e a existência do sistema de rating ${ }^{9}$ e a determinação de certos parâmetros que ensejarão procedimentos gerenciais ou disciplinares (iv). A análise de todos os requisitos levantados pela autora mostra que, na relação existente entre o motorista e a empresa, há subordinação sob um falso pretexto de liberdade de escolha, pois os motoristas são verdadeiramente livres para escolher breves coisas. Além disso, a onerosidade é perceptível na "troca" do serviço pelo retorno financeiro que a empresa gera. Também é possível apontar a habitualidade, principalmente, em algumas modalidades onde há um número mínimo de viagens ${ }^{10}$. Por fim, a pessoalidade encontra-se no fato da pessoa escolher o motorista, que é qualificado, ranqueado, detém suas informações no aplicativo e presta seu serviço como pessoa física. Vale mencionar que se os motoristas desempenham um verdadeiro papel de empresário individual, mesmo desenvolvendo a atividade como pessoa física, seria necessário o registro com Cadastro Nacional de Pessoas Jurídicas (CNPJ) na junta comercial ${ }^{11}$, o que não é exigido.

Tal situação é muito similar ao caso da empresa Ifood. Sob um pretexto de revolucionar o da alimentação por meio da tecnologia, o site institucional da empresa ${ }^{12}$ elenca uma série de benefícios em desenvolver uma "parceria”, como o fornecimento de plano de saúde, a existência de uma campanha para o

\footnotetext{
${ }^{9}$ Em poucas palavras, o rating é um sistema de avaliação mútua: tanto os motoristas parceiros como os usuários avaliam uns aos outros, atribuindo estrelas, com baseados na viagem.

${ }^{10} \mathrm{Em} 2019$, a Uber anunciou uma nova categoria, em que além do motorista ter um número mínimo de viagens exigido, o passageiro pode pedir para que ele não fale. Para saber mais: G1. Uber anuncia nova categoria no Brasil que permite passageiro escolher se quer viagem sem conversa. São Paulo, 07/10/2019. Disponível em:

https://g1.globo.com/economia/tecnologia/noticia/2019/10/07/uber-anuncia-nova-categoria-no-brasil-que-permite-passageiroescolher-se-quer-viagem-sem-conversa.ghtml

${ }^{11}$ É o que dispõe o art. 967 do Código Civil de 2002: “é obrigatória a inscrição do empresário no Registro Público de Empresas Mercantis da respectiva sede, antes do início de sua atividade".

${ }^{12}$ Cadastrado no seguinte endereço eletrônico: https://institucional.ifood.com.br/nossa-entrega/.
} 
oferecimento de gorjetas (apesar dar gorjeta ser estritamente ligada ao consumidor e não haver a participação da plataforma) e a possibilidade de gerar uma renda extra para aquele que se interessar. Em comparação com a Uber, os requisitos para se cadastrar como entregador no Ifood são mais flexíveis. Segundo informações presentes no seu site institucional, é necessário: i) Ter mais de 18 anos; ii) Possuir plano de dados 3G; iii) Contar com um veículo para a entrega; iv) Comprar a sua caixa térmica ou báu próprio; e v) Ser detentor de uma conta bancária (IFOOD, 2020). Caso o entregador não disponha de motocicleta, é facultado a possibilidade de realizar as entregas utilizando uma bicicleta, desde que o interessado possua um Registro Geral (RG) que tenha sido emitido nos últimos 10 (dez) anos. Assim como não é disponibilizado pela empresa a caixa térmica (ou o báu) e o pacote de dados exigido que são indispensáveis para a realização da atividade, também não é cedido o veículo ou realizado algum tipo de auxílio na sua manutenção, financiamento ou combustível.

Nos Termos de Uso ${ }^{13}$ do aplicativo há outras disposições que evidenciam a dinâmica da relação, pois o entregador está obrigado a: indenizar o iFood por quaisquer danos, prejuízos, responsabilização, reclamações, processos, perdas, demandas ou despesas, incluindo, mas não se limitando a isso, honorários advocatícios, custas judiciais e ônus de sucumbência decorrentes da utilização indevida da Plataforma (4.1.vi); e assumir a responsabilidade pelas multas, penalidades e processos administrativos/judiciais referentes às entregas realizadas (4.1.ix). Desde o início, assim como os motoristas do aplicativo Uber, recai sob o entregador do Ifood todas as despesas, custos, taxas, tributos e contribuições referentes aos equipamentos técnicos/operacionais essenciais para a função (entrega), além do veículo, da jaqueta, da luva, do capacete (que fazem parte da legislação de trânsito) (4.1.vii).

$\mathrm{Na}$ relação desempenhada entre o entregador do aplicativo e a empresa Ifood, encontra-se configurada a mesma subordinação sob um falso pretexto de liberdade de escolha. Primeiro, não é possível negociar o valor recebido por cada entrega já que o seu cálculo é realizado automaticamente por meio de um algoritmo (7.1). O que também é inegociável é, ao concordar com os Termos de Uso, reconhecer que o Ifood não é uma empresa de transporte ou operação logística, servindo apenas para disponibilizar uma plataforma tecnológica que possibilita a colaboração entre os que desempenham atividades relacionadas (2.2.3). Isso se desenvolve, de acordo com a empresa, em um ambiente de autonomia e independência por não ser exigido ter disponibilidade ou periodicidade para a execução das atividades de entrega e por não haver nenhum tipo de fiscalização (2.4). Ainda a despeito de desobrigar a habitualidade e afirmar que o entregador é livre para aceitar ou recusar a entrega, a empresa poderá desativar a conta do entregador por um determinado período de tempo, sem justificativa ou aviso prévio, quando aparentar que o empregador não tem disponibilidade para realização da atividade (9.3.2). Na prática, não há uma determinação objetiva de qual seria o período de ausência que pode ser considerado passível de haver a desativação da conta, interpretando-se que a habitualidade é uma maneira de evitar o desligamento e que existe, de fato, uma fiscalização constante.

${ }^{13}$ É possível acessá-lo em: https://entregador.ifood.com.br/termosdeuso/ 
A tecnologia possibilitou a criação de um modelo de negócio em que a empresa consegue lucrar com o trabalho alheio minimizando consideravelmente as despesas econômicas. Fazendo apenas o gerenciamento da plataforma tecnológica (o aplicativo) e entrando em contato diretamente com os clientes, a relação principal aparenta ser entre o aplicativo e o consumidor final, sem envolver os parceiros. Essa "parceria" tratase de uma relação em que um lado possui todo o aparato material, a capacidade de determinar unilateralmente os termos do vínculo (inclusive o valor do pagamento) e o outro possui todo o dispêndio de tempo, de força de trabalho e de exposição direta ao cliente. Esse simulacro se intitula como autonomia, liberdade e empreendedorismo individual esconde e desumaniza a peça essencial da relação: o entregador/motorista. Sem o seu trabalho, é inviável o funcionamento dos aplicativos, mas ele continua recebendo menos pelo serviço, não possuindo direitos mínimos garantidos e precisando arcar com todos os encargos jurídicos, materiais e econômicos.

A economia do compartilhamento é uma das diversas expressões que surgiram para nomear os fenômenos complexos e múltiplos gerados pela utilização da tecnologia disruptiva no cotidiano. De acordo com Silva (2018), uma utilização eficiente dos produtos e serviços que estão disponíveis é o ponto principal da economia compartilhada, além do fato de que compartilhar um bem, ou um serviço, congrega valores sociais, econômicos e ambientais. Sendo assim, as duas empresas, Uber e Ifood, revolucionaram os seus respectivos setores, facilitando o cotidiano de diversas pessoas que passaram a utilizar os seus serviços. Isso se deve às potencialidades da comunicação digital em rede para fazer com que mais pessoas consumam produtos e serviços a partir da troca e/ou do compartilhamento e com melhorias para o ambiente (BARROS; PATRIOTA, 2017). Porém, apesar das facilidades e dos benefícios já enumerados, a utilização tecnológica não resultou também em um avanço no patamar de proteção à parte hipossuficiente da relação.

A exposição à baixa remuneração, a longas jornadas e à ausência de reconhecimento do vínculo trabalhista entre motoristas e entregadores e suas respectivas empresas pode implicar em diversas violações. Se, em um primeiro momento, o que se reveste de importância é estabelecer condições mínimas e dignas de exercício diário (como o estabelecimento de uma jornada e de uma remuneração mínima), a indefinição do tipo de vínculo e o vácuo normativo específico para regular a temática impõe impasses futuros que repercutem diretamente na vida das pessoas envolvidas, como a falta de uma disposição acerca dos acidentes de trabalho ou da garantia do recebimento da aposentadoria.

A Constituição Federal de 1988, no art. 7, impõe como direitos de todos os trabalhadores, entre outros: o recebimento de seguro-desemprego (ii); o pagamento de salário mínimo (iv) e a garantia de que o salário recebido nunca será inferior a ele (vii); uma remuneração do trabalho noturno superior ao diurno (ix); uma duração de jornada que não seja superior a oito horas diárias (xiii); que o repouso semanal seja remunerado (xv); a aposentadoria (xxiv). Essas garantias visam à melhoria das condições sociais dos trabalhadores e foram redigidas para atender às necessidades humanas de cada empregado. Como já mencionado anteriormente, alguns entregadores de aplicativo, durante a pandemia, chegaram a exercer uma jornada diária de $12 \mathrm{~h}$ de serviço, sem ajuste em relação ao trabalho noturno e sem repouso semanal 
remunerado. A questão é que o ordenamento legal deve ser aplicado em sua organicidade, pois negar ao trabalhador um período de descanso mínimo, uma remuneração que permita a sua subsistência e um tempo de férias remuneradas, p. ex, é uma maneira de impossibilitar o acesso a diversos outros direitos, como o direito à educação e à cultura.

Existe uma ampla proteção constitucional e infraconstitucional para todos os trabalhadores, mas a sua insuficiência em atingir a nova categoria de funcionários só pode ser entendida ao analisar a estruturação das empresas e o recorte histórico ao qual elas estão inseridas. Ocorre que, como já falado, o avanço tecnológico ressignificou as relações de trabalho em menor ou maior grau, dependendo da categoria de análise. Assis (2018), aponta que a influência da sociedade tecnológica e informacional, e a reestruturação produtiva e racionalização promovem mudanças nas relações laborais que, causam, inevitavelmente, o impasse de flexibilização dos direitos trabalhistas. Apesar de ser possível argumentar que o ordenamento jurídico está diante de um vácuo normativo que impossibilita balizar a regulamentação dessa nova categoria de trabalhadores, o que precisa ser realizado é a atribuição de novos significados à legislação trabalhista que sejam coerentes às modificações ocorridas na sociedade.

Relevando o fato de que reconhecer o preenchimento dos requisitos de uma relação trabalhista pode apresentar uma margem ampla de subjetividade, o debate sobre essa indeterminação, no mundo informacional, perpassa sobre a necessidade de repensar o conceito de subordinação. As condições sob as quais os serviços desempenhados pelos motoristas e entregadores de aplicativos se desenvolvem evidenciam a mudança no contexto social. Seja ao falar da empresa Uber ou do Ifood, a subordinação não está mais acontecendo nos moldes tradicionais e se manifesta, p. ex., na impossibilidade de negociar a taxa recebida (que fica a cargo de um método algorítmico) e na virtualização da fiscalização (que pode resultar em desligamento do aplicativo ou no bloqueio temporário). A negação dessa situação, e a própria invisibilização da categoria é uma maneira de violar os direitos trabalhistas e dificultar a fiscalização por parte das instituições.

Segundo Moraes Júnior (2018), é com a perspectiva de flexibilização que se potencializa a regulação, através de políticas econômicas, mas especialmente da legislação trabalhista, para reduzir as compensações usuais antes estabelecidas aos trabalhadores. Dessa maneira, a legislação trabalhista deixa seu leito, seu eixo natural, que é o de proteção e de servir como uma das formas de atenuar a exclusão social. O avanço tecnológico não pode ensejar o enfraquecimento de conquistas históricas ou a criação de categorias de serviço que, transvestidas de novas formas de negócio, precarizam e desumanizam as relações trabalhistas. Mais do que uma demanda pelo reconhecimento do vínculo, a questão representa também um impacto direto na identificação desses trabalhadores como tais. Sem haver a criação dessa identidade comum, dificulta-se a própria mobilização da sociedade civil e o pleiteamento de direitos, o que pode explicar a dificuldade na unificação das pautas que são levantadas quando ocorre algum protesto.

Sabendo que, inevitavelmente, as mudanças estruturais da sociedade geram a flexibilização e o desmonte de direitos trabalhistas, é preciso analisar e acompanhar o entendimento desenvolvido pela 
jurisprudência doméstica sobre o assunto. Já é possível apontar a existência de diversas ações que visam determinar a existência (ou não) de vínculo trabalhista entre a empresa e o motorista/entregador. Tal cenário se repete nos Tribunais estrangeiros ${ }^{14}$.

\section{O VÍNCULO DOS MOTORISTAS/ENTREGADORES PARCEIROS: O ENTENDIMENTO JURISPRUDENCIAL ACERCA DA (IN)EXISTÊNCIA DA RELAÇÃO EMPREGATÍCIA}

Apesar do tema ser novo em território doméstico, há várias ações judiciais em relação às empresas Uber e Ifood provenientes da seara trabalhista e da cível. O grande número de ações demonstra que, atualmente, a temática é conflituosa. Nas próximas subseções será feito um levantamento da jurisprudência que discute, mesmo transversalmente, a existência (ou não) do vínculo de trabalho entre os motoristas/entregadores e as plataformas tecnológicas aos quais estão vinculados. Assim, será possível observar qual é o estágio da construção de um entendimento e uma interpretação comum, por parte dos tribunais, acerca do tema.

\subsection{O perfil jurisprudencial envolvendo as ações trabalhistas em desfavor da empresa Uber}

O comportamento decisório das instâncias inferiores aponta, mesmo timidamente, para uma tendência em reconhecer o vínculo trabalhista ${ }^{15}$. Foi assim que a $28^{\mathrm{a}}$ Vara do Trabalho De Porto Alegre decidiu na Ação Trabalhista n. 0021864-81.2017.5.04.0028 em 02 de março de 2020. A ação, ajuizada por Alexandre Roberto de Oliveira em desfavor da empresa Uber, pleiteava o reconhecimento da existência de vínculo de emprego, o que ocasionaria a consequente condenação da empresa à anotação da Carteira Nacional de Trabalho e Previdência Social (CTNPS) e ao pagamento dos outros direitos trabalhistas atinentes.

A sentença ${ }^{16}$ começa destacando que o fato de ser uma "plataforma digital" não afasta automaticamente a existência do vínculo trabalhista, já que "se a relação de trabalho evoluiu nas últimas décadas, a forma de analisar as mais diversas facetas que o trabalho humano assume também pode ser reconstruída a partir de princípios próprios do direito laboral” (BRASIL, 2020b, p. 26). O juiz prossegue

\footnotetext{
${ }^{14}$ Não é o foco deste trabalho adentrar no entendimento das Cortes dos outros países, mas para saber mais sobre os precedentes internacionais acerca da existência de vínculo trabalhista e os conflitos estatais envolvendo o aplicativo Uber, ver: SANDERS, Sam. California Labor Commission Rules Uber Driver Is An Employee, Not A Contractor. 17/06/2015. Disponível em: http://www.npr.org/sections/thetwo-way/2015/06/17/415262801/california-labor-commission-rules-uber-driver-is-anemployee-not-a-contractor; DRAY, Guilherme; PONTE, Joana. Tribunal Francês reconhece vínculo laboral entre a UBER e Motorista. 14/01/2019. Disponível em: https://www.macedovitorino.com/xms/files/2019/20190114Acordao_Tribunal_Frances_Uber.pdf.

${ }^{\overline{15}}$ Além dos casos que serão analisados na subseção, vale mencionar outros que foram favoráveis ao reconhecimento do vínculo trabalhista, como a Reclamação Trabalhista n. 1001492-33.2016.5.02.0013 ajuizada na $13^{\text {a }}$ Vara do Trabalho de São Paulo e a Reclamação Trabalhista n. 0011359-34.2016.5.03.0112 que tramitou na 33 ${ }^{\text {a }}$ Vara do Trabalho de Belo Horizonte. No entanto, até agora, todas as sentenças que que apontaram a relação empregatícia foram reformadas nas instâncias superiores para declarar a inexistência do vínculo de trabalho ou estão pendentes o julgamento dos recursos.

${ }^{16}$ Atualmente o processo foi remetido ao Tribunal Regional do Trabalho da $4^{\text {a }}$ região para que seja julgado o recurso ordinário interposto pela reclamada.
} 
definindo que toda prestação trabalhista induz em seu bojo a presunção de que está sendo desenvolvida sob um vínculo empregatício e descreve a existência de todos os requisitos trabalhistas na relação desenvolvida entre o motorista de aplicativo e a empresa Uber. Quanto à subordinação, essa se manifesta, entre outras coisas, na exigência de documentação específica ao se cadastrar e a possibilidade de desligamento caso a nota média do motorista esteja baixa. O fato de a conta ser individual demonstra a pessoalidade da função. Em relação à onerosidade, restou-se comprovada devido aos pagamentos recebidos pelas viagens realizadas. Por fim, é possível observar a habitualidade quando se considera que há o controle da frequência do motorista através de GPS e, sem a realização do trabalho, não há o repasse de nenhum valor.

No mesmo sentido, em 05 de março de 2020, decidiu a $86^{\text {a }}$ Vara do Trabalho de São Paulo. A sentença $^{17}$ aponta a existência dos requisitos que configuram uma relação trabalhista (onerosidade, pessoalidade, subordinação e habitualidade) em uma fundamentação muito similar ao caso narrado anteriormente, mas se diferencia ao apontar de que maneira a empresa subverte a lógica dos fatos concretos. Pois, ao contrário do que é afirmado, "não há como admitir que a reclamada (Uber) atua no mercado apenas como uma empresa de tecnologia, se não recebe qualquer receita decorrente da licença de uso de seu software, que por sua decisão, foi cedido de forma gratuita aos clientes/motoristas”(BRASIL, 2020c, p. 12).

Ainda sobre a sentença, um outro fato apontado como inviabilizador da alegação da Uber de ser uma empresa tecnológica é a sua relação com os motoristas ser fundada contrato de adesão onde se exime de todas as responsabilidades relacionadas aos erros da plataforma. Então, apesar de se declarar uma intermediadora de negócios, a natureza contratual faz com que ela estabeleça todas as cláusulas e diretrizes do negócio que será desenvolvido pelo motorista, suposto “dono do negócio". Na prática, para ele, só resta a opção de concordar com todos os termos ou não ser aceito. Não é possível, portanto, negociar o preço da prestação do serviço, é a empresa que "define a contraprestação do valor de seu próprio serviço - de intermediação - e pode alterar unilateralmente o valor da taxa de serviço a qualquer momento e a seu exclusivo critério" (BRASIL, 2020c, p. 13).

A comparação entre o comportamento decisório das instâncias inferiores e dos tribunais é relevante ao indicar que, ao contrário do que é possível observar nos juízos de primeiro grau, os tribunais predominantemente negam a existência do vínculo trabalhista ${ }^{18}$. No caso mais recente, em 09 de setembro de 2020, a $4^{\mathrm{a}}$ turma do Tribunal Superior do Trabalho negou a existência do vínculo de trabalho entre a empresa Uber e o seu motorista. $\mathrm{O}$ acórdão nega a existência do vínculo de trabalho com base na justificativa de que o trabalho pela plataforma tecnológica não atende aos critérios definidos nos artigos $2^{\circ}$ e $3^{\circ}$ da CLT devido à liberdade do motorista em decidir quando irá disponibilizar o seu serviço de transporte para os usuáriosclientes, à ausência de exigência de um número mínimo de viagens por período, de faturamento ou de trabalho

\footnotetext{
${ }^{17}$ A reclamação trabalhista está em sede recursal, tramitando no Tribunal Regional do Trabalho da 2 a Região e com relatoria do Des. Paulo Kim Barbosa.

18 “Ao todo, 935 ações com esse pedido chegaram aos tribunais regionais do trabalho. O mérito foi julgado em $258 \mathrm{casos}$. Em apenas cinco deles (menos de $2 \%$ ) o pleito foi considerado procedente; em $172(66 \%)$, totalmente improcedente. E outros 81 litígios (31\%) tiveram como desfecho a procedência parcial do pedido." (CONSULTOR JURÍDICO, 2020).
} 
(BRASIL, 2020e). Além disso, para o órgão colegiado, não é possível vislumbrar fiscalização ou punição por qualquer decisão do motorista.

Para fundamentar a referida decisão, uma das referências utilizadas foi o julgamento do Recurso de Revista n. 10000123-89.2017.5.02.0038 pela $5^{\mathrm{a}}$ turma do Tribunal Superior do Trabalho (TST) que também negou o vínculo empregatício entre a empresa Uber e o motorista. No dia 07 de fevereiro de 2020, a $5^{a}$ turma ponderou os fatos e achou determinante a possibilidade de ficar off-line, sem uma limitação de tempo, para comprovar que não havia a subordinação. Para eles, isso mostra que, na prática, há ampla flexibilidade do autor em determinar sua rotina, seus horários de trabalho, locais que deseja atuar e a quantidade de clientes que pretende atender por dia (BRASIL, 2020d). Essa liberdade serviu para diferenciar o serviço prestado pelos motoristas, típico de um trabalhador autônomo, da subordinação obrigatória que os empregados possuem.

Por fim, foi frisado que o intento da proteção ao trabalhador não se sobrepõe às formas de trabalho emergentes de maneira que possa impedi-las, já que elas são pautadas em critérios menos rígidos e que permitem maior autonomia na sua consecução, mediante livre disposição das partes (BRASIL, 2020d). Apesar da afirmação categórica, vale pontuar que um dos vieses da proteção social trabalhista objetiva exatamente evitar retrocessos em garantias conquistadas historicamente. Nesse sentido dispõe o Princípio da proibição do retrocesso social, extraído do art. $7^{\circ}$ da Constituição Federal de 1988, interpretado, segundo Corrêa (2012), não apenas como uma faculdade à existência de outros direitos, pois ele determina à sociedade uma busca constante da melhoria das condições dos trabalhadores por meio da instituição de novas normas. Essa busca incessante pela melhoria das condições trabalhistas é incompatível com a falsa dicotomia entre a proteção do trabalhador e às novas formas de trabalho, pois a prioridade constitucional é a parte hipossuficiente e vulnerável da relação: o empregado.

O grande número de ações ajuizadas mostra que as saídas apontadas pelo judiciário, predominantes em negar a existência do vínculo, não estão atendendo aos interesses dos motoristas. Os diversos dissensos jurisprudenciais, a ausência de um entendimento consolidado e/ou de decisão com efeito vinculante no Supremo Tribunal Federal (STF) é sintomático de uma situação indefinida e que precisa de um amplo debate jurídico e social. Mesmo diante desse cenário, a discussão acerca da situação jurídica dos motoristas de aplicativo está mais avançada do que a dos entregadores, os quais começaram a recorrer ao judiciário substancialmente no ano de 2020.

\subsection{A proteção judicial dos entregadores de aplicativo}

Algumas particularidades do serviço desempenhado pelos entregadores de aplicativo os diferenciam dos motoristas. Como já exposto anteriormente, a dinâmica do trabalho e os termos acordados diferem, mas a suposta mediação através de uma plataforma digital é a mesma. O que ensejou diversas ações que pleiteiam o reconhecimento do vínculo trabalhista. De acordo com levantamento do Datalawyer, até o dia 
14 de setembro de 2020, 582 ações foram apresentadas contra os aplicativos Uber, iFood, Loggi e Rappi, o que representa um aumento de 52\% em relação às taxas registradas em 2019 (FOLHADE PERNAMBUCO, 2020). Foi destacado que até o ano de 2020 não havia especificação em relação a quais aplicativos estavam sendo processados, até que as ações ajuizadas pelos motoristas de aplicativo passaram a ter mais expressão, principalmente, impulsionadas pelo sentimento de mobilização decorrente do Breque dos Apps.

Apesar de haver muitas ações que estão pendentes de julgamento e o número das que foram ajuizadas em relação à aplicativos de entrega de alimentos ser bem menor, já houve uma decisão notória que tratou especificamente da empresa Ifood e do possível vínculo existente entre ela e os seus entregadores. No julgamento da Ação Civil pública de n. 1000100-78.2019.5.02.0037, a 37 vara do Trabalho de São Paulo decidiu por declarar a inexistência de relação empregatícia. Em sua sentença reconheceu que a atividade faz parte da área tecnológica ao explorar um aplicativo de internet que possibilita ao restaurante receber pedidos e ao entregador/motofretista prestar serviços de entrega, ficando este com um percentual do valor da operação paga integralmente pelo comprador da refeição, e não sendo a oferta de transporte de mercadorias a atividade primordial do aplicativo (BRASIL, 2020a). Nessa forma de atuação, a Ifood é a tomadora do serviço de entregadores, portanto, atua por meio da terceirização da atividade de entregador. Isso ocorre, pela leitura da juíza, pelas possibilidades do entregador conhecer a distância e o valor que será pago e poder escolher a rota (intermediada pelo aplicativo) que preferir.

Tal precedente não foi suficiente para encerrar a controvérsia, que continua gerando o ajuizamento de diversas ações. Para entender qual será a solução do impasse jurídico, será necessário observar de que maneira será decidida os casos que estão pendentes e os que ainda surgirão. No atual estágio, não é possível vislumbrar perspectivas de soluções devido à posição enrijecida que alguns tribunais e juízos ainda desenvolvem que, mesmo ao afirmarem as mudanças trazidas pela tecnologia, não trazem uma visão verdadeiramente atualizada e adaptada à realidade. Diante da indefinição, os trabalhadores continuam em um limbo jurídico de incerteza e insegurança.

\section{CONSIDERAÇÕES FINAIS}

Os diversos avanços tecnológicos revolucionaram a forma de viver e de se relacionar em sociedade. Apesar dos benefícios notórios, o aumento no aparato tecnológico não gerou melhorias nas condições de trabalho dos empregados e fez emergir novas formas de trabalho que, metamorfoseadas em empreendedorismo individual, difundem a naturalização de que o pagamento de qualquer valor está dentro da realidade. As empresas Uber e Ifood, plataformas tecnológicas que revolucionaram seus setores, representam de maneira padrão esse paradigma. Os motoristas e entregadores desses aplicativos são considerados "parceiros" e não empregados, o que inviabiliza, em tese, a configuração do vínculo de trabalho. Ainda nesse interim, tenta-se banalizar jornadas excessivas com o falso pretexto de liberdade de escolher o tempo de serviço e de ausência de fiscalização. Na prática, para conseguir uma remuneração que garanta a mínima 
sobrevivência, o dispêndio excessivo de força de trabalho é praticamente obrigatório e a fiscalização ocorre de maneira virtualizada, o que faz com que ela pareça imperceptível em uma análise superficial.

O fato é que se tornou inviável utilizar os mesmos parâmetros que balizaram a aplicação do direito do trabalho, no século XX, nas relações desenvolvidas na sociedade da informação. A subordinação está presente sob outros aspectos, e só pode ser entendida utilizando como pano de fundo as revoluções tecnológicas. Posto isso, não é necessária uma nova legislação, mas uma perspectiva hermenêutica em que a norma se adapte às mudanças estruturais da sociedade levando em conta toda a sua dinamicidade. A atribuição desses novos significados à legislação trabalhista, que leva em consideração a existência de rating, de monitoramento por GPS e de outras especificidades trazidas pela tecnologia, permitirá uma revolução a partir dos próprios princípios do direito do trabalho.

O que se observa ao analisar a jurisprudência doméstica é o estágio atual da discussão: a ausência de consenso, o elevado número de ações, as diversas contradições interpretativas e a dificuldade em desenvolver (e consolidar) um entendimento comum evidenciam a zona de incerteza que permeia a questão da (in)existência do vínculo de trabalho entre entregadores/motoristas e as plataformas digitais que eles são contratados. Enquanto os debates envolvendo a empresa Uber estão mais avançados e já resultaram em diversas decisões, a empresa Ifood começou a ser alvo recorrente de processos trabalhistas consideravelmente no ano de 2020. De qualquer maneira, em nenhum dos casos é possível apontar uma solução para o dilema, já que os dissensos doutrinários têm se mostrado a regra. A observação do comportamento jurisprudencial dos próximos anos é imprescindível para mostrar qual será o entendimento que irá preponderar no direito brasileiro.

Mais do que reconhecer a existência do vínculo (ou não), é necessário reconhecer a vulnerabilidade aos quais esses trabalhadores (motoristas e entregadores) estão submetidos. A indefinição gera insegurança jurídica, posterga a solução da questão e contribui para um quadro de incerteza que é incompatível com um Estado que tem como fundamento os valores sociais do trabalho.

\section{REFERÊNCIAS BIBLIOGRÁFICAS}

ASSIS, Vinicius. A proibição de retrocesso social em matéria de direitos sociais dos trabalhadores: análise da (in)constitucionalidade da reforma trabalhista. 2018. Dissertação. (Programa de Pós-graduação em Direito, Área de concentração: Direito Econômico e desenvolvimento) - Pontifícia Universidade Católica do P a r a n á, C u r i t i b a, 20018 . https://sucupira.capes.gov.br/sucupira/public/consultas/coleta/trabalhoConclusao/viewTrabalhoConclusao. jsf?popup=true\&id_trabalho $=6894716$.

BARROS, Ana Cirne Paes; PATRIOTA, Karla Regina Macena Pereira. Consumo colaborativo: perspectivas, olhares e abordagens para um conceito em construção. Signos do Consumo, São Paulo, v. 9, n. 2 , p. 4-15, jul./dez. 2017. 
BBC. Coronavírus: entregadores de aplicativo trabalham mais e ganha menos na pandemia, diz pesquisa. Por Felipe Souza e Leandro Machado. 07/05/2020. Disponível em: https://www.bbc.com/portuguese/brasil-52564246Acesso em 05 out. 2020.

BRASIL. 37 $7^{\text {a }}$ ara do Trabalho de São Paulo. Ação Civil Pública n. 1000100-78.2019.5.02.0037. Autor: Ministério Público Do Trabalho. Réu: Rapiddo Agencia De Servicos De Entrega Rapida S.A., Ifood.Com Agencia De Restaurantes Online S.A. Juíza: Shirley Aparecida De Souza Lobo Escobar. São Paulo, 27 de janeiro $\quad$ d e $\quad 2020$ a $\quad$ D is poníve $1 \quad$ e m : https://migalhas.uol.com.br/arquivos/2020/1/06A8F4826FBD66_decisaoifood.pdfAcesso em 08 out. 2020. BRASIL. $28^{\mathrm{a}}$ Vara do Trabalho de Porto Alegre. Reclamação trabalhista n. 0021864-81.2017.5.04.0028. Reclamante: Alexandre Roberto de Oliveira. Reclamado: Uber Do Brasil Tecnologia Ltda. Juiz: Atila da Rold Roesler. Porto A legre, 02 de março de 2020 b. Disponíve 1 e m : https://pje.trt4.jus.br/consultaprocessual/detalhe-processo/0021864-81.2017.5.04.0028 Acesso em 07 out. de 2020.

BRASIL. $86^{\text {a }}$ Vara do Trabalho de São Paulo. Reclamação trabalhista n. 1000540-24.2019.5.02.0086. Reclamante: Marcos Dos Santos Queiroz. Reclamado: Uber Do Brasil Tecnologia Ltda., Uber International B.V., Uber International Holding B.V. Juíza: Raquel Marcos Simões. São Paulo, 05 de março de 2020c. Disponível em: https://pje.trt2.jus.br/consultaprocessual/detalhe-processo/10005402420195020086 Acesso em 08 out. 2020 .

BRASIL. Tribunal Superior do Trabalho. $5^{\text {a }}$ Turma. Processo n. TST-RR-10000123-89.2017.5.02.0038. Relator: Ministro Breno Medeiros. Brasília, 5 de fevereiro de 2020d. Acesso em: < http://www.tst.jus.br/>. Disponível em: 10 jun. 2020.

BRASIL. Tribunal Superior do Trabalho. $4^{\text {a }}$ Turma. Processo n. TST-AIRR-10575-88.2019.5.03.0003. Relator: Alexandre Luiz Ramos. Brasília, 09 de setembro de 2020e. Disponível em: https://www.conjur.com.br/dl/processo10575-8820195030003.pdfAcesso em 08 out. de 2020.

BRASIL. Decreto-Lei n ${ }^{\circ}$ 5.442, de 01 de maio de 1943. Consolidação das Leis do Trabalho. Brasília, DF, 01 mai. 1943.

BRASIL. Constituição (1988). Constituição da República Federativa do Brasil de 1988. Brasília, DF, out. 1988.

BRASIL. Lei nº 10.406, de 10 de janeiro de 2002. Institui o Código Civil. Diário Oficial, Brasília, DF, 11 jan. 2002.

CHRISTENSEN, H. V. C. Disruptive Innovation. Disponível em: http://claytonchristensen.com/keyconcepts/Acesso em 10 fev. 2020 
CONSULTOR JURÍDICO. Entregadores perdem maioria dos casos sobre vínculo empregatício com aplicativos. 24/07/2020. Disponível em: https://www.conjur.com.br/2020-jul-24/entregadores-perdemmaioria-casos-vinculo-aplicativos Acesso em: 08 out. 2020.

CORREA, Carlos Romeu Salles. O princípio da proibição do retrocesso social no direito do trabalho, 2012. Dissertação. (Mestrado em Direito) - Faculdade de Direito da UFBA.

DAVIS, Gerald Frederick. What might replace the modern corporation? Uberization and the web page enterprise. Seattle University Law Review, 39, p. 501-515, 2016. Disponível em: http://digitalcommons.law.seattleu.edu/cgi/viewcontent.cgi?article=2314\&context=sulr. Acesso em 01 out. 2020.

DRAY, Guilherme; PONTE, Joana. Tribunal Francês reconhece vínculo laboral entre a UBER e Motorista. 14/01/2019. Disponível em: https://www.macedovitorino.com/xms/files/2019/20190114_Acordao_Tribunal_Frances_Uber.pdfAcesso em 07 out. 2020.

REVISTA PEQUENAS EMPRESAS E GRANDE NEGÓCIOS. Trabalhador enfrenta fila de espera para se tornar entregador em aplicativo. Por Estadão conteúdo. 19/07/2020. Disponível em: https://revistapegn.globo.com/Banco-de-ideias/Aplicativos/noticia/2020/07/pegn-trabalhador-enfrentafila-de-espera-para-se-tornar-entregador-em-aplicativos.html Acesso em: 05 out. 2020.

FOLHA DE PERNAMBUCO. Ações por vínculo de emprego com apps já superam total de 2019. Por Folhaexpress. Publicado em 15/09/2020. Disponível em: https://www.folhape.com.br/economia/acoes-porvinculo-de-emprego-com-apps-ja-superam-total-de-2019/154769/ Acesso em: 08 out. 2020.

FOLHA DE SÃO PAULO. Entregadores defendem preço mínimo por corrida unificado a todos os apps. Por Fernanda Brigatti e Paula Soprana. Publicado em 01/07/2020a. Disponível em: https://www1.folha.uol.com.br/mercado/2020/07/entregadores-defendem-preco-minimo-por-corridaunificado-a-todos-os-apps.shtml Acesso em 23 set. 2020.

FOLHA DE SÃO PAULO. Manifestações de entregadores dura 7 horas em São Paulo. Por Paula Soprana e Fernanda Brigatti. Publicado em 01/07/2020b. Disponível e m: https://www1.folha.uol.com.br/mercado/2020/07/protesto-de-entregadores-comeca-com-cerca-de-1000motoboys-na-marginal-pinheiros.shtml Acesso em 20 jul. 2020.

G1. Uber anuncia nova categoria no Brasil que permite passageiro escolher se quer viagem sem conversa. São Paulo, 07/10/2019. Disponível em:

https://g1.globo.com/economia/tecnologia/noticia/2019/10/07/uber-anuncia-nova-categoria-no-brasil-quepermite-passageiro-escolher-se-quer-viagem-sem-conversa.ghtml Acesso em 07 out. 2020.

IFOOD. Ajuda com o cadastro no APP. Publicado em 07/08/2020. Disponível em: 
https://entregador.ifood.com.br/cadastro-ifood/Acesso em 28 set. 2020.

KRAMER, Josiane Caldas. A economia compartilhada e a uberização do trabalho: utopias do nosso tempo?. 2018. Dissertação (Pós-Graduação em Direito, Setor de Ciências Jurídicas), Universidade Federal do Paraná, Curitiba, 2019.

MORAIS, Vitória Larissa Dantas; AMARAL, Maria Teodora Rocha Maia; REIS, Ulisses Levy Silvério. A Pandemia da Covid-19 e as Obrigações Empresariais em Matéria de Direitos Humanos: a empresa Uber frente à garantia do mínimo existencial para os trabalhadores. In: Ana Maria D'Ávila Lopes; Antonio Jorge Pereira Júnior; Mônica Carvalho Vasconcelos. (Org.). Direitos Humanos e Empresas em Tempos da Pandemia da COVID-19. 01 ed. Porto Alegre: Livraria do Advogado, 2020, v. 01, p. 249-267

SANDERS, Sam. California Labor Commission Rules Uber Driver Is An Employee, Not A Contractor. 17/06/2015. Disponível em: http://www.npr.org/sections/thetwo-way/2015/06/17/415262801/californialabor-commission-rules-uber-driver-is-an-employee-not-a-contractor Acesso em 07 out. 2020.

SILVA, Karoline Barboza. Economia de compartilhamento: novas relações de consumo e a jurisprudência regulatória. 2018. Dissertação (Programa de pós-graduação em ciências jurídicas - Área de concentração: Direito Econômico - Linha 2: Estado, Mercado, Sujeitos Sociais: juridicidade e economicidade) Universidade Federal da Paraíba, João Pessoa, 2018.

UBER, E. Fatos e dados sobre a Uber. Disponível em: https:/www.uber.com/pt-BR/newsroom/fatos-edados-sobre-uber/ Acesso em 10 fev. 2020

UNIVERSO ONLINE. Motoristas da Uber no Brasil aderem à greve mundial e vão parar por 24h. Por Gabriel Francisco Ribeiro. Publicado em: 07/05/2019. Disponível em: https://www.uol.com.br/tilt/noticias/redacao/2019/05/07/motoristas-da-uber-no-brasil-aderem-a-grevemundial-e-vao-parar-por-24h.htm Acesso em 23 set. 2020 